KONSTAN
JURNAL FISIKA DAN PENDIDIKAN FISIKA
Volume 5, Nomor 2, Desember 2020
E-ISSN : 2460-9129 dan P-ISSN : 2460-9110
http://jurnalkonstan.ac.id/index.php/jurnal

\title{
PENERAPAN PEMBELAJARAN BERBANTUAN EDMODO TERHADAP HASIL BELAJAR SISWA PADA KONSEP GEJALA PEMANASAN GLOBAL
}

\author{
Nurcahyani Podungge ${ }^{1)}$, Dewi Diana Paramata ${ }^{1)}$, Abdul Haris Odja ${ }^{1)^{*}}$ \\ 1) Program Studi Pendidikan Fisika, Fakultas MIPA Universitas Negeri Gorontalo \\ J1. Jendral Sudirman No.6 Gorontalo, Indonesia 96128
}

\section{Info Artikel \\ Sejarah Artikel: \\ Diterima 13 November 2020 \\ Disetujui 30 Desember 2020 \\ Dipublikasikan 31 \\ Desember 2020}

\section{Kata Kunci:}

Kata kunci E-learning,

Edmodo, Hasil Belajar,

Gejala Pemanasan Global

\begin{abstract}
Abstrak
Penelitian ini bertujuan untuk memberikan gambaran mengenai apakah terdapat pengaruh penerapan e-learning berbantuan media pembelajaran Edmodo terhadap hasil belajar siswa pada materi gejala pemanasan global, yang dilakukan di MAN 1 Kota Gorontalo pada tahun ajaran 2019/2020 dengan menggunakan kelas XI IPA 4 sebagai sampel penelitian. Metode penelitian yang digunakan yaitu metode eksprimen dengan desain One Group Pretest-Posttest Design. Teknik pengumpulan data menggunakan tes tertulis berupa pretest dan posttest, data yang terkumpul dilakukan uji n-gain dengan nilai rata-rata hasil belajar pada posttest adalah 64 sedangkan pada pretest adalah 17 artinya nilai posttest lebih tinggi dibandingkan nilai pretest sehingga terjadi peningkatan hasil belajar. Sedangkan nilai n-gain yang ternormalisasi adalah 0.637 dan termasuk dalam kategori sedang. Selanjutnya dilakukan uji hipotesis menggunakan uji " $t$ " berpasangan diperoleh $t_{\text {hitung }}$ sebesar 31.22 sedangkan nilai diperoleh sebesar 2.03951. Dengan demikian $t_{\text {hitung }}>t_{\text {tabel }}$ sehingga $\mathrm{H}_{0}$ : ditolak dan $\mathrm{H}_{1}$ : diterima. Hal ini menunjukan bahwa terdapat perbedaan yang signifikan pada hasil belajar siswa sebelum dan setelah menerapkan e-learning dalam pembelajaran fisika berbasis al-quran pada konsep gejala pemanasan global.
\end{abstract}

(C) 2020 Universitas Islam Negeri Mataram

* Corresponding Author: abdulharis@ung.ac.id

Alamat korespodensi:

Gedung Pasca Sarjana Lantai 3 Kampus 2 UIN Mataram, Jl. Gajah Mada 100 Jempong Mataram, Indonesia

Email: jurnalkonstan@uinmataram.ac.id 


\section{PENDAHULUAN}

Pendidikan adalah bentuk upaya yang dilaksanakan oleh setiap orang sehingga bisa memajukan kemampuannya dengan proses belajar mengajar. Saat ini pendidikan merupakan satu hal yang sangat penting untuk diraih karena pendidikan dapat menentukan kualitas diri seseorang, sehingga pendidikan sering dimaknai sebagai tolak ukur kesuksesan [1].

Ada beberapa hal yang dapat menunjang keberhasilan mutu pendidikan, yaitu dengan adanya teknologi. Baik teknologi ataupun pendidikan merupakan sesuatu yang tidak bisa dipisahkan, karena peranan teknologi sangatlah penting dalam dunia pendidikan begitupun sebaliknya [2]. Dalam penggunaan teknologi waktu yang diberikan oleh siswa pada dunia maya sangatlah besar, sehingga kita perlu khawatir dengan perilaku siswa yang menjadi kurang produktif karena penggunaan gadget yang dapat mengakibatkan penyalagunaan teknologi. Oleh karena itu kita perlu untuk memanfaatkan teknologi dengan baik, terutama dalam pendidikan.

Agar penggunaan teknologi informasi dan komunikasi dapat digunakan secara efektif dalam pendidikan, maka dalam melaksanakan suatu proses pembelajaran diperlukan strategi yang tepat. Proses belajar mengajar yang sering kita jumpai di kelas biasanya mengunakan pembelajaran tatap muka (face-to-face). Sehingga saat ini perlu memanfaatkan teknologi dengan proses pembelajaran online (e-learning). Karena proses pembelajaran yang hanya memanfatkan tatap muka (face-to-face) tidak dapat sepenuhnya berhasil, hal tersebut karena gaya belajar masing-masing siswa berbeda [3].

Untuk mengatasi masalah tersebut maka penulis mengharapkan penerapan e-learning dalam pembelajaran fisika pada materi gejala pemanasan global. $E$ learning adalah model pembelajaran yang difasilitasi dengan memanfaatkan teknologi informasi dan komunikasi (TIK) [4]. Proses pembelajaran tatap muka (face to face) sama pentingnya dengan e-learning, terbukti saat ini e-learning menjadi salah satu alternatif pembelajaran yang sedang digunakan hampir diseluruh dunia [4].

Sejak terjadinya pandemi Covid-19 yang terjadi di seluruh dunia, seluruh pengajar diwajibkan melaksanakan aktivitas pembelajaran dari rumah. Pembelajaran E-learning merupakan salah satu yang diwajibkan di dunia pendidikan dari tingkat SD sampai perguruan tinggi. Di Universitas secara umum telah memiliki sistem pembelajaran E-learning yang dibuat, tetapi aktivitas sangat terbatas. Khusus untuk Universitas Negeri Gorontalo telah memiliki pembelajaran e-learning melalui SIAT. Tanggap darurat Covid-19 membuat dosen dan mahasiswa wajib mempelajari dan melaksanakan pembelajaran daring [2]. Dengan adanya penerapan $e$-learning kita tetap dapat melaksanakan pembelajaran walaupun tetap dirumah dan waktu yang digunakanpun tidak terabatas sehingga siswa tidak merasa bosan untuk belajar fisika. Seperti yang kita ketahui bahwa fisika ialah pelajaran yang dirasa cukup sulit oleh kebanyakan siswa, karena pelajaran fisika hanya selalu tentang rumus dan perhitungan.

Pernyataan tersebut selaras dengan pernyataan berikut yaitu pelajaran fisika adalah pelajaran yang sulit dikerjakan dan tidak mudah dipahami. Sebagian besar dari siswa menyatakan bahwa fisika sangatlah sulit karena lebih banyak rumus daripada konsep. Selain itu, mereka kesulitan mempelajari fisika karena metode 
pembelajaran yang terksesan membosankan dan guru terlalu cepat ketika menjelaskan materi [5].

Tugas besar seorang pengajar fisika adalah menjadikan pelajaran fisika lebih menarik yaitu dengan mengguakan metode pembelajaran yang sesuai, sehingga penerapan e-learning menjadi salah satu alternatif. Agar penerapan $e$ learning, dapat efektif maka pemilihan media pembelajaran harus tepat. Dalam penelitian ini peneliti memilih aplikasi Edmodo sebagai media pembelajaran.

Sistem pembelajaran online atau e-learning merupakan model baru dalam proses pembelajaran. E-learning adalah sebab dan akibat yang masuk akal dari perkembangan teknologi informasi dan komunikasi, karena adanya e-learning siswa tidak perlu lagi duduk di ruang kelas untuk menerima pembelajaran secara tatap muka. E-learning juga dapat menghemat jadwal target waktu belajar mengajar dan selain itu juga pastinya menghemat biaya yang harus dikeluarkan oleh sebuah program pendidikan [6]. E-learning adalah gambaran model pembelajaran yang didukung dan difasilitasi oleh pemanfaatan teknologi informasi dan komunikasi [7].

Pembelajaran berbasis e-learning adalah pembelajaran yang memanfaatkan TIK, e-learning tersebut membawa dampak terbentuknya suatu proses perubahan pendidikan formal ke dalam bentuk digital. E-learning adalah salah satu media dengan memanfaatkan aplikasi internet yang dapat menyatukan siswa dan guru dalam proses belajar mengajar di kelas daring, yang sangat mendasar dari e-learning yaitu bahwa dalam proses belajar mengajar, baik guru maupun siswa tidak dapat dipisahkan entah dari segi tempat ataupun waktu [8].

Pemanfaatan teknologi informasi e-learning yang salah satunya melalui web ataupun aplikasi yang digunakan dalam pembelajaran akan membawa perubahan yang sangat baik dalam pembelajaran, aplikasi yang digunakan misalnya seperti Edmodo sebagai media dalam pembelajaran e-learning [9].

Edmodo adalah platform microbloggingpribadi yang dikembangkan untuk guru dan siswa, dengan mengutamakan privasisiswa. Guru dan siswa dapat berbagi catatan, tautan, dan dokumen [10]. Di dalam Edmodo ini, bisa berlangsung pembelajaran antara guru dan siswa, bahkan orang tua bisa mengkontrol anaknya saat pembelajaran berlangsung [11].

Penggunaan Edmodo dengan metode E-Learning cukup baik memberikan atau mempengaruhi keterampilan mahasiswa dalam menggunakan fitur-fitur di Edmodo baik keterampilan membuat akun, menggunakan profil Edmodo, quiz, assignment, note, maupun mengakses nilai $[12,13,14]$.

Berdasarkan hasil penelitian [15], Ha (Hipotesis Alternatif) menyatakan bahwa ada pengaruh penerapan media Edmodo terhadap hasil belajar PAI di SMK Anwarul Maliki Sukorejo Pasuruan. Hal ini dibuktikan dari hasil perhitungan Uji T Paired Test yang menunjukkan nilai signifikan 0.000, karena signifikan $<0.05$ maka dapat disimpulkan bahwa Ho ditolak dan Ha (Hipotesis Alternatif) diterima. Yang artinya rata-rata nilai sebelum dan sesudah penerapan media Edmodo adalah ada pengaruh.

Hasil penelitian lain menyebutkan bahwa menggunakan Edmodo dapat meningkatkan minat dan hasil belajar pada materi kelarutan dan hasil kali kelarutan [16]. Lebih lanjut [17] mengungkapkan bahwa ketuntasan hasil belajar siswa dengan menerapkan model Blended Learning pada materi larutan penyangga sebesar $80,95 \%$ dengan kategori sangat baik. 
Dari hasil penelitian [18], terdapat perbedaan yang signifikan antara pembelajaran menggunakan E-learning Edmodo pada kelas eksperimen dengan pembelajaran menggunakan metode konvensional pada kelas kontrol terhadap hasil belajar siswa kelas X pada mata pelajaran ekonomi materi pasar modal di SMA Negeri 4 Bangkalan, artinya pembelajaran dengan menggunakan media E-learning Edmodo memiliki pengaruh yang positif terhadap hasil belajar siswa [19].

\section{METODE PENELITIAN}

Metode penelitian yang digunakan dalam penelitian ini adalah penelitian Eksperimen dengan bentuk desain eksperimen One Group Pretest-Posttest Design. Populasi dalam penelitian ini yaitu seluruh siswa kelas XI MAN 1 Kota Gorontalo yang terdaftar sebagai siswa tahun pelajaran 2019/2020. Pengambilan sampel dalam penelitian ini menggunakan cluster random sampling, jadi sampel terpilih dalam penelitian ini adalah kelas XI IPA 1 di MAN 1 Kota Gorontalo.

Instrumen penelitian yang digunakan dalam penelitian ini yaitu tes tertulis berupa pretest dan posttest dalam bentuk essay untuk melihat hasil belajar siswa ranah kognitif. Teknik analisis data menggunakan uji $\mathrm{N}$-gain sebagai berikut:

$$
N \text {-gain }=\frac{\text { Nilai Post }- \text { test }- \text { niali } \text { pre-tes }}{\text { nilai maksimal }- \text { nilai } p r e-\text { test }}
$$

Setelah dilakukan perhitungan, hasil yang di dapatkan kemudian diintepretasi berdasarkan kriteria seperti pada tabel 1 berikut:

Tabel 1 Kriteria pengelompokan $N$-gain

\begin{tabular}{cc}
\hline Indeks Gain & Kriteria \\
\hline $\mathrm{g}>0,70$ & Tinggi \\
\hline $0,30<\mathrm{g}<0,70$ & Sedang \\
\hline $\mathrm{g}<0,30$ & Rendah \\
\hline
\end{tabular}

Untuk mengetahui kuatnya hubungan antara variabel, yaitu dilakukan uji hipotesis dengan analisis data menggunakan teknik analisis statistik uji $t$ berpasangan dengan rumus :

$$
\mathrm{t}=\frac{\bar{D}}{\sqrt{\frac{\sum D^{2}-\frac{\left(\sum D^{2}\right)}{N}}{N(N-1)}}}
$$

keterangans:

$\mathrm{t}=$ harga $\mathrm{t}$ untuk sampel berkorelasi

$\bar{D}=($ difference $)$, perbedaan antara sekor tes awal dengan sekor tes akhir setiap individu

$\mathrm{D}=$ rerata dari nilai perbedaan (rerata dari $\mathrm{D})$ 
$\mathrm{D}^{2}=$ kuadrat dari $\mathrm{D}$

$\mathrm{N}$ = banyaknya subjek penelitian [20]

\section{HASIL DAN PEMBAHASAN}

\section{A. Hasil Penelitian}

Penelitian ini dilaksanakan di MAN 1 Kota Gorontalo dengan menggunakan 1 kelas sebagai sampel penelitian yaitu kelas XI IPA 4 dengan hasil nilai siswa sebagai berikut.

Tabel 2. Data Hasil Nilai Siswa Pada Pretest dan Postest

\begin{tabular}{|c|c|c|}
\hline \multirow{2}{*}{ Responden } & \multicolumn{2}{|c|}{ Nilai } \\
\hline & Pretest & Postest \\
\hline Responden 1 & 18.43 & 65.95 \\
\hline Responden 2 & 12.05 & 54.6 \\
\hline Responden 3 & 5.67 & 49.64 \\
\hline Responden 4 & 15.6 & 75.17 \\
\hline Responden 5 & 9.21 & 80.85 \\
\hline Responden 6 & 14.89 & 70.92 \\
\hline Responden 7 & 14.89 & 58.15 \\
\hline Responden 8 & 12.05 & 77.3 \\
\hline Responden 9 & 12.76 & 66.66 \\
\hline Responden 10 & 8.51 & 77.3 \\
\hline Responden 11 & 5.67 & 65.95 \\
\hline Responden 12 & 5.67 & 51.06 \\
\hline Responden 13 & 6.38 & 75.17 \\
\hline Responden 14 & 5.67 & 74.46 \\
\hline Responden 15 & 21.27 & 77.3 \\
\hline Responden 16 & 12.05 & 72.34 \\
\hline Responden 17 & 6.38 & 63.12 \\
\hline Responden 18 & 12.05 & 74.46 \\
\hline Responden 19 & 6.38 & 71.64 \\
\hline Responden 20 & 9.21 & 73.75 \\
\hline Responden 21 & 9.21 & 47.51 \\
\hline Responden 22 & 13.47 & 77.3 \\
\hline Responden 23 & 30.49 & 65.95 \\
\hline Responden 24 & 8.51 & 70.92 \\
\hline Responden 25 & 9.92 & 63.82 \\
\hline Responden 26 & 15.6 & 77.3 \\
\hline Responden 27 & 7.09 & 70.92 \\
\hline
\end{tabular}




\begin{tabular}{ccc}
\hline \multirow{2}{*}{ Responden } & \multicolumn{2}{c}{ Nilai } \\
\cline { 2 - 3 } & Pretest & Postest \\
\hline Responden 28 & 17.02 & 50.35 \\
\hline Responden 29 & 8.51 & 66.66 \\
\hline Responden 30 & 6.38 & 69.5 \\
\hline Responden 31 & 15.6 & 70.92 \\
\hline Responden 32 & 3.5 & 62.41 \\
\hline
\end{tabular}

Untuk melihat efek peningkatan hasil belajar siswa dengan penerapan Edmodo maka perlu dilakukan pengolahan dan analisis data pretest dan posttest dengan menggunakan uji n-gain yang ternormalisasi sehingga diperoleh skor ratarata tes hasil belajar siswa pada Tabel 2 .

Tabel 3. Rekapitulasi Nilai Tes Hasil Belajar Siswa

\begin{tabular}{|c|c|c|c|c|c|c|}
\hline \multirow{2}{*}{ Tes } & \multirow{2}{*}{$\begin{array}{l}\text { Nilai } \\
\text { Ideal }\end{array}$} & \multirow{2}{*}{$\begin{array}{l}\text { Nilai } \\
\text { Maks }\end{array}$} & \multirow{2}{*}{$\begin{array}{l}\text { Nilai } \\
\text { Min }\end{array}$} & \multirow{2}{*}{$\begin{array}{l}\text { Rata- } \\
\text { Rata }\end{array}$} & \multicolumn{2}{|c|}{$\langle\mathrm{g}\rangle$} \\
\hline & & & & & Nilai & Kriteria \\
\hline Pretest & 100 & 30.49 & 3.5 & 17 & \multirow{2}{*}{0.637} & \multirow{2}{*}{ Sedang } \\
\hline Posttest & 100 & 80.85 & 47.52 & 64 & & \\
\hline
\end{tabular}

Berdasarkan Tabel 3 dapat dilihat bahwa terjadi peningkatan hasil belajar siswa sebelum dan sesudah diberikan perlakuan yaitu menerapkan $e$-learning dalam pembelajaran dengan menggunakan aplikasi Edmodo. Hal tersebut dibuktikan dengan nilai rata-rata hasil belajar yang diperoleh pada posttest adalah 64 sedangkan nilai rata-rata pada pretest adalah 17 artinya nilai posttest lebih tinggi dibandingkan nilai pretest sehingga terjadi peningkatan hasil belajar. Sedangkan nilai $\mathrm{n}$-gain yang ternormalisasi adalah 0.637 dan termasuk dalam kategori sedang dan diketahui bahwa hasil pretest dan posttest yaitu $\mathrm{L}_{\text {hitung }}<\mathrm{L}_{\text {tabel }}$ pada taraf signifikan $\alpha=0.05$. Hal ini menunjukan bahwa data dari pretest dan posttest berdistribusi normal.

Untuk Pengujian hipotesis ini menggunakan rumus uji-t berpasangan. Hasil perhitungan tersebut dapat dilihat pada Tabel 4.

Tabel 4 Hasil Uji-t Berpasangan Pretest dan Posttest

\begin{tabular}{ccccc}
\hline Variabel & Sampel & $\mathrm{t}_{\text {hitung }}$ & $\mathrm{t}_{\text {tabel }}$ & Kesimpulan \\
\hline Pretest-Posstest & 32 & 31.22 & 2.03951 & $\begin{array}{c}\mathrm{H}_{0}: \text { Ditolak } \\
\mathrm{H}_{1}: \text { Diterima }\end{array}$ \\
\hline
\end{tabular}

Berdasarkan tabel 4 dapat dilihat bahwa hasil pengujian hipotesis menggunakan uji $t$ berpasangan diperoleh $t_{\text {hitung }}$ sebesar 31.22 sedangkan nilai $t_{\text {tabel }}$ pada $\alpha=0.05 ; \mathrm{df}=31(32-1)$ diperoleh sebesar 2.03951. Dengan demikian $\mathrm{t}_{\text {hitung }}>$ $t_{\text {tabel }}$ atau $t_{\text {hitung }}=31.22$ lebih besar dari $t_{\text {tabel }}=2.03951$ sehingga Ho : ditolak dan Hi : diterima. Jadi dapat disimpulkan bahwa terdapat pengaruh hasil belajar siswa sebelum menerapkan e-learning berbantuan media pembelajaran Edmodo terhadap ahsil belajar siswa pada materi gejala pemanasan global. 


\section{B. Pembahasan}

Penelitian ini bertujuan untuk mengetahui pengaruh penerapan e-learning berbantuan media pembelajaran Edmodo terhadap hasil belajar siswa pada materi gelaja pemanasan global. Penelitian ini merupakan jenis penelitian eksperimen dengan menggunakan 1 kelas sebagai sampel peneltian. Lokasi yang digunakan yaitu di MAN 1 Kota Gorontalo yaitu pada kelas XI IPA 4. Berdasarkan data yang telah diperoleh, peneliti melakukan analisis data pada pretest dan posttest didapatkan bahwa hasil nilai rata-rata pretest yaitu 17 dan nilai rata-rata posttest yaitu 64, sedangkan nilai n-gain yang ternormalisasi adalah 0.637 dan termasuk dalam kategori sedang. Jadi dapat diketahui bahwa terjadi peningkatan yang signifikan antara hasil belajar pretest sebelum di berikan perlakuan dan posttest setelah diberikan perlakuan.

Hasil belajar yang meningkat dipengaruhi metode mengajar yang dibuat dengan semenarik mungkin. Salah satu yang menunjang keberhasilannya yaitu dengan pemilihan media atau aplikasi yang digunakan dalam mengajar, sehingga peneliti memilih aplikasi Edmodo. Sama halnya dengan penelitian yang sebelumnya [6], dengan hasil penelitian yaitu penggunaan media pembelajaran yaitu aplikasi Edmodo memiliki pengaruh dapat meningkatkan hasil belajar siswa, yaitu dari nilai rata-rata 66.79 menjadi 80.10 . Selanjutnya dari hasil pretest dan posttest dilakukan uji normalitas sehingga didapatkan bahwa data tersebut berdistribusi normal.

Setelah dilakukan uji normalitas, dilanjutkan dengan pengujian hipotesis. Berdasarkan hasil pengujian hipotesis pretest dan posttest diketahui bahwa penerapan e-learning berbantuan media pembelajaran Edmodo berpengaruh terhadap hasil belajar siswa pada materi gejala pemanasan global. Hal tersebut dibuktikan dengan hasil uji hipotesis menunjukan bahwa $t_{\text {hitung }}>t_{\text {tabel }}$ atau $t_{\text {hitung }}=$ 31.22 lebih besar dari $t_{\text {tabel }}=2.03951$ sehingga Ho : ditolak dan Hi : diterima.

Hasil tersebut sesuai dengan penelitian sebelumnya [8], yang menunjukkan nilai rata-rata pre-test $26,56 \%$ dan setelah perlakuan meningkat sebanyak $51,57 \%$ menjadi $78,13 \%$. Persentase ketuntasan klasikal kemampuan berpikir kritis siswa sebesar $85 \%$ dalam kategori baik. Nilai rata-rata keseluruhan pengaruh penggunaan e-learning pemanfaatan Edmodo terhadap peningkatan prestasi belajar siswa menggunakan $\mathrm{N}$-gain $(\mathrm{g})$ adalah 0,70 dengan kriteria sedang. Jumlah siswa yang memperoleh nilai di atas 75 berdasarkan standar kelulusan minimal sebanyak 17 siswa, sedangkan yang memperoleh nilai di bawah 75 sebanyak 3 siswa.

\section{SIMPULAN DAN SARAN}

Berdasarkan analisis data hasil penelitian dapat disimpulkan bahwa penerapan e-learning berbantuan media pembelajaran edmsodo berpengaruh terhadap hasil belajar siswa. Hal ini ditunjukan dengan adanya perbedaan yang signifikan pada hasil belajar siswa sebelum dan sesudah penerapan. Pada nilai ratarata hasil belajar yang diperoleh pada posttest adalah 64 sedangkan nilai rata-rata pada pretest adalah 17 artinya nilai posttest lebih tinggi dibandingkan nilai pretest sehingga terjadi peningkatan hasil belajar. Hal lainnya juga dapat dilihat dari pengujian hipotesis yang menunjukan bahwa $t_{\text {hitung }}>t_{\text {tabel }}$ atau $t_{\text {hitung }}=31.22$ lebih besar dari $t_{\text {tabel }}=2.03951$ sehingga Ho : ditolak dan Hi : diterima. Peningkatan hasil belajar tersebut dipengaruhi oleh berbagai faktor salah satunya yaitu media pembelajaran yang digunakan yaitu Edmodo, dengan demikian dapat diketahui bahwa aplikasi Edmodo berpengaruh terhadap hasil belajar siswa. 
Diharapkan kepada guru agar kiranya dapat menerapkan e-learning dalam pembelajaran dan juga pihak sekolah hendaknya memberikan dukungan dengan menyediakan fasilitas untuk menunjang proses pembelajaran e-learning.

\section{DAFTAR PUSTAKA}

[1] Anshori, AF., Sukmawati, S. 2019. Pengaruh Penggunaan Aplikasi Edmodo Terhadap Efektivitas Pembelajaran Mahasiswa Pendidikan Biologi. Jurnal Pendidikan Biologi. p-ISSN 2573-5163 e-ISSN 2579-7085. Vol 4 (2)

[2] Arota A., Mursalin., AH, Odja. 2020. The effectiveness of e-learning based on SETS to improve students' critical thinking skills in optical instrument material. Journal of physics: Conference Series. Conf. Ser. 1521022062.

[3] YA Hadjarati, AS Arota, Mursalin dan AH Odja. 2020. Effectiveness of Edmodo to improve senior high school students' creative thinking skills in momentum and impulse topics. Journal of Physics: Conference Series 1521 (2020) 022065.

[4] Budiman, Haris. 2017. Peran Teknologi Informasi dan Komunikasi Dalam Pendidikan. Jurnal Pendidikan Islam. Vol.8 (2) ISSN-p : 2086 9188, ISSN-e : $25282476,32$.

[5] Hanum, Numiek Sulistyo. 2013. Keefektifan E-Learning Sebagai Media Pembelajaran. Jurnal Pendidikan Vokasi. Vol 3 (1), 92.

[6] Azizah, Rismatul., dkk. 2015. Kesulitan Pemecahan Fisika Pada Siswa SMA. Jurnal Penelitian Fisika dan Aplikasinya (JPFA). 2015. Vol 2. No.2. 46

[7] Silahuddin. 2015. Penerapan E-Learning Dalam Inovasi Pendidikan. Jurnal Ilmiah Circuit. Vol 1 (1), 51.

[8] Hanum, Numiek Sulistyo. 2013. Keefektifan E-Learning Sebagai Media Pembelajaran. Jurnal Pendidikan Vokasi. Vol 3 (1), 92.

[9] Bakri, Fauzi \& Mulyati, Dewi. 2017. Pengembangan Perangkat E-Learning Untuk Matakuliah Fisika Dasar Ii Menggunakan Lms Chamilo. Jurnal Wahana Pendidikan Fisika. Vol.2 (1). ISSN: 2338-1027, 25.

[10] Usman, B. (2016). Jurnal Ilmiah Ilmu Pendidikan, Ilmu Ekonomi, dan Ilmu Sosial. Jurnal EKSIS, 12(1), 3295-3298.

[11] Nurdani, Alif Rahardhika. 2016. Penggunaan Media Edmodo Untuk Meningkatkan Hasil Belajar Siswa Pada Mata Pelajaran Dasar-Dasar Perhitungan Survei Pemetaan Kelas X Geomatika SMK N 3 Salatiga dan SMK $N 1$ Kedungwuni Pekalongan. Semarang: Fakultas Teknik Uneversitas Negeri Semarang.

[12] Sudibjo, Ari, Wasis. 2013. Penggunaan Media Pembelajaran Fisika dengan ELearningBerbasis Edmodo Blog Educationpada Materi Alat Optik untuk Meningkatkan Respons Motivasi dan Hasil Belajar Siswa di SMP Negeri 4 Surabaya. Jurnal Inovasi Pendidikan Fisika. 2 (3): 188.

[13] M Murjainah, \& Utomo, B. 2018. Pengaruh Praktikum Sistem Informasi Geografis Terhadap Kemampuan Mahasiswa Pendidikan Geografi Dalam Membuat Peta Berbasis Arcgis. Jurnal Swarnabhumi. Vol.3 No.1.I

[14] Rahmawaty, Santhy Putri., dkk. 2017. Penggunaan Media Pembelajaran Edmodo Untuk Meningkatkan Aktivitas dan Hasil Belajar Siswa Kelas X. Jurnal Pendidikan Ekonomi. Vol.11 (1). ISSN: 1907-9990. 
[15] Wardani, Deklara Nanindya., dkk. 2018. Daya Tarik Pembelajaran Di Era 21 Dengan Belended Learning. Jurnal Kajian Teknologi Pendidikan. Vol.1 (1), ISSN: 2615-8787, 13-14.

[16] Budhi, J. 2013. Penerapan Blended Learning dengan Number Heads Together untuk Meningkatkan Minat dan Prestasi Belajar pada Materi Kelarutan dan Hasil Kali Kelarutan Siswa Kelas XI IPA 1 SMAN Gondangrejo Tahun Ajaran 2012/2013. Jurnal Pendidikan Kimia. Vol II. No 4. 96-101

[17] Afdhila, R., Nazar, M., \& Hanum, L. (2017). Penerapan Pembelajaran Blended Learning Pada Materi Larutan Penyangga di SMA Negeri 1 Unggul Darul Imarah. Jurnal Ilmiah Mahasiswa Pendidikan Kimia (JIMPK). Vol 2 No 3, 165-172.

[18] Pratama, Moch Dwi Wahyudy., Aspodo Tjipto Subroto. 2017. Pengaruh Penggunaan Edmodosebagai Media Pembelajaran E-Learningterhadap Hasil Belajar Siswa Pada Materi Pasar Modal Mata Pelajaran Ekonomi Kelas X SMA.Vol. 2. No. 2.

[19] Maghfiroh, Nuril Wilda., Askhabul Kirom., Munif. 2018. Pengaruh Penerapan Media Edmodo Terhadap Hasil Belajar Pendidikan Agama Islamdi Smk Anwarul Maliki Sukorejo Pasuruan. Jurnal Al-Ghazwah. Issn: 20852894. Vol.2, No.2

[20] Arikunto, Suharsimi. 2013. Menajemen Penelitian. Jakarta: Rineka Cipta. 